Proceedings of the 2013 Winter Simulation Conference

R. Pasupathy, S.-H. Kim, A. Tolk, R. Hill, and M. E. Kuhl, eds

\title{
AN ONLINE SIMULATION TO LINK ASSET CONDITION MONITORING AND OPERATIONS DECISIONS IN THROUGH-LIFE ENGINEERING SERVICES
}

\author{
Benny Tjahjono \\ Manufacturing \& Materials Department \\ Cranfield University \\ Cranfield, Bedford MK43 0AL, UK
}

\author{
Evandro Leonardo Silva Teixeira \\ Faculdade Gama \\ Universidade de Brasília \\ Área Especial de Indústria Projeção A \\ Gama 72.444-240, Brazil
}

\author{
Sadek Crisóstomo Absi Alfaro \\ Grupo de Automação e Controle \\ Departamento de Engenharia Mecânica \\ Universidade de Brasília \\ Brasília 70.910-900, Brazil
}

\begin{abstract}
This paper presents an online simulation framework that can be used to support operational decisions within the context of Through-life Engineering Services. Acting as a closed-loop feedback control mechanism, the simulation model is physically coupled to the assets and will be triggered and automatically executed to assess a set of operational decisions related to maintenance scheduling, resource allocation, spare parts inventory etc. Experimental cases comparing the online simulation against the traditional approach will also be presented. The outcomes have demonstrated the prospects of the framework in enabling more effective/efficient operations of engineering services leading to high assets availability and reduced through-life costs.
\end{abstract}

\section{INTRODUCTION}

The last decade saw the emergence of a new manufacturing paradigm whereby many high-tech Original Equipment Manufacturers (OEMs) have shifted their business focus from offering high value products to offering an integrated products/assets and services. High value assets (e.g. aero engines, machines, trains, wind turbines, etc.) are typically technology intensive, reliability-critical and therefore require engineering services throughout their long life cycle. This new business model enables the customers to buy the 'capability' of the assets (typically) through a contractual agreement whilst the ownership of the assets remains within the OEM. The responsibility of the OEM is now extended beyond manufacturing of the assets to cover maintenance and services throughout the life cycle of the assets. The OEM is obliged to guarantee that the assets are always up and running or else the penalties might be imposed by their customers. The OEM must continuously monitor the condition of the assets being contracted out and take any necessary actions before the assets break down. 


\section{Tjahjono, Teixeira, and Alfaro}

Through-life engineering services are hereby defined as all the services related to engineering activities to ensure the assets are 'healthy', available and ready to operate in order to accomplish the mission. Although the engineering services typically include maintenance, repair and overhaul, their boundary naturally extends to embrace quality inspections, spare parts inventory, information systems, resource allocation etc. High quality provision of engineering services will therefore not only depend on the design of the service operations but also on the timely services required so as to minimize the total through-life costs.

This paper presents an online simulation framework that can support more effective and efficient operational decision making in the context of through-life engineering services.

\section{LITERATURE REVIEW}

Engineering services require an integrated offering drawing upon resources from both customers and suppliers to deliver additional values for engineering assets, people and technology ( $\mathrm{Ng}$ et al. 2011). Engineering services comprise a new way of thinking, business model, process, organization, tools and information management (Purchase, Parry, and Mill 2011). In a business model based on engineering services, the OEMs need to ensure asset performance throughout the life of the assets.

The business requirements from the through-life engineering services must consider the rights and obligations set up in the service contract. The business requirements are assessed through performance indicators, and one of the typical performance measures recognized by both OEMs and their customers is availability (Lindahl et al. 2005). Rausand and Hoyland (2004) defined availability as the ability of an asset (under combined aspect of its reliability, maintainability and maintenance support) to perform its required function at an instant of time or over a period of time. To ensure the desired asset performance, it is therefore essential to utilize the current asset information in order to predict the asset behavior and possible fault condition (Ouertani, Parlikad and McFarlane 2008). For this reason, asset monitoring data is crucial when unplanned downtime on high value assets can lead to the total system failure that is obviously costly and hazardous to environment or even life-threatening (Tu et al. 2007).

Condition monitoring, diagnosis and prognosis function provides an effective engineering service delivery (Dausch and Hsu 2006). In particular, condition monitoring also promotes the means of reducing (or eliminating) unnecessary repairs, prevent catastrophic failures and reduce the negative impact of the maintenance operation on the profitability of manufacturing (Mobley 2002). Based on the condition monitoring, the service provider can assess the current asset performance throughout the entire asset lifetime.

In through-life engineering services, an effective management of the asset lifetime is essential for the success of the business goals. An effective asset lifetime management requires not only the effective design of service activities, which comprise installation, maintenance, repair, overhaul, etc., (Goffin and New 2001), but also their optimized operational decisions. Discrete-event simulation has traditionally been used to aid in the validation of the systems design including engineering services operations (Mattila, Virtanen, and Raivio 2008) with the goal to better understand their behavior and ultimately to improve their overall performance (Benedettini and Tjahjono 2009).

However, despite the potential benefits, the use of simulation modeling within the engineering services remains challenging in many aspects. Firstly, simulation modeling is inherently a design tool and typically there is no direct coupling between the simulation model and the actual system. Once the system is in operations, there is no further need to use the simulation model. Secondly, experimentation of the simulation model needs to be initiated from a state that corresponds to the actual state of the current system and bringing the model to this state of the model is challenging. Thirdly, the reliability data, such as breakdown and other stoppages, are usually taken from historical data or approximated using probability distribution functions, represented by the Mean Time Between Failures (MTBF). Maintenance activities that do not consider the change in asset conditions due to operational and environmental influence can lead to asset failures and unscheduled asset stoppages (Markeset and Kumar 2003). 
Online simulation uses some type of feedback mechanism to couple the model and the actual system. It adopts similar principles used in real-time control systems where the simulation model is applied in a feedback loop. One distinct feature of an online simulation is that the parameters obtained from the actual system will become a set of the current state of that system which, in turn, will be used to initialize the simulation model. This feature, consequently, enables the simulation model to be used not only during the design phase of engineering service, but more importantly can be extended to the operational stage where the model can be used as a day-to-day operational tool (Hanisch, Tolujew, and Schulze 2005). Online simulation provides operational decision support in order to evaluate short-term decisions, to adjust the business strategies due to contextual changes or unforeseen circumstances (Wynn et al. 2008).

\section{SIMULATION OF ENGINEERING SERVICES}

Figure 1 shows a block diagram of the proposed online simulation framework. In this framework, the simulation model of engineering services is physically coupled with the actual operations of engineering services, as the outcomes of the simulation will be used as a basis of the decisions.

The simulation model represents the operations and management of engineering services which include maintenance, service and overhaul activities, and the types of decision supported by the model are, for instance, resource allocation, spare part delivery policy, maintenance scheduling etc. One distinct feature of the online simulation is that the monitored parameters of the actual system will become a set of current state parameters of the simulation model which in turn will initialize the simulation model and immediately execute the predetermined experimental scenarios set by the decision makers/modelers. In this setting, the framework will assume that the assets have condition monitoring systems.



Figure 1: Framework to implement the online simulation

\subsection{Reliability Estimator}

The Reliability Estimator (RE) receives the signals from the condition monitoring systems and predicts the health of the assets in terms of their reliability. It determines the likelihood of failure based on predefined operating time period. Using asset condition data and the operating boundaries defined beforehand, the RE estimates what the reliability performance of the assets will be. The reliability performance, also known as mission reliability, can be defined as the conditional probability from such component/system to execute its function effectively for the next time frame taking into account the current degradation level (Lu, Kolarik, and Lu 2001).

The second-order exponential smoothing (Holt's linear trend model) was the estimation technique adopted to implement the RE kernel, simply because it does not need a parametric model fitting (Gelper, Fried, and Croux 2010) and also it has similar estimation accuracy compared to other techniques, e.g. Kalman Filter and Extended Kalman Filter (LaViola 2003). The second-order exponential smoothing can be mathematically described as (Yar and Chatfield 1990): 


$$
\begin{gathered}
\theta_{i}=\gamma_{1} \mathrm{~h}_{\mathrm{i}}+\left(1-\gamma_{1}\right)\left(\theta_{\mathrm{i}-1}+\Omega_{\mathrm{i}-1}\right) \\
\Omega_{i}=\gamma_{2}\left(\theta_{\mathrm{i}}-\theta_{\mathrm{i}-1}\right)+\left(1-\gamma_{2}\right) \Omega_{\mathrm{i}-1}
\end{gathered}
$$

where

$\mathrm{h}_{\mathrm{i}}=$ Performance degradation data at time $i$

$\theta_{i}=$ Level component of the estimation at time $i$

$\Omega_{\mathrm{i}}=$ Trend component of the estimation at time $i$

$\gamma_{1}=$ Local mean smoothing constant

$\gamma_{2}=$ Local trend smoothing constant

The mean and the trend constant can be selected within the interval $(0,1]$ (NIST/SEMATECH 2011). Once the smoothing constants are chosen, the 1-step-ahead estimation can be taken from the following formula:

$$
\hat{\mathrm{h}}_{\mathrm{i}+l \mathrm{i}}=\theta_{\mathrm{i}}+l \Omega_{\mathrm{i}}
$$

where

$\hat{\mathrm{h}}_{\mathrm{i}+l \mathrm{i}}=l$-step-ahead performance estimation at time $i$

The 1-step-ahead error variance can be obtained, recursively, from the one-step-ahead error variance as (Lu, Kolarik, and Lu 2001; Yar and Chatfield 1990):

$$
\begin{gathered}
\hat{v}_{\mathrm{i}+l \mathrm{i}}^{2}=\left\{1+\frac{1}{6}(l-1) \cdot \gamma_{1}^{2} \cdot\left[1+l \gamma_{2}+l(2 l-1) \gamma_{2}^{2}\right]\right\} \hat{v}_{1}^{2} \\
\hat{v}_{1}^{2}=\sum_{i=p+1}^{q-1} \frac{\vartheta_{1}^{2}}{q-1-p} \\
\vartheta_{1}=h_{\mathrm{i}+1}-\hat{h}_{i+1 \mid i}
\end{gathered}
$$

where

$\hat{v}_{\mathrm{i}+l \mathrm{i}}^{2}=l$-step-ahead error variance

$\hat{v}_{1}^{2} \quad=$ One-step-ahead error variance

$\vartheta_{1}=$ One-step-ahead estimation error

$p+1=$ Start time for the estimation

$q-1=$ End time for the estimation

An experiment was carried out in order to validate the RE kernel. A critical limit $(20 \%$ above the performance degradation limit) was chosen to be the lower bound limit which enables the maintenance action to be taken before the asset's failure. Figure 2 shows the RE experimental validation.

Once the last asset data are received, the estimation algorithm estimates the performance degradation trend for 8-steps-ahead. Using the estimation of the performance degradation, the RE kernel calculates the current conditional reliability. Table 1 shows the RE experimental results. For 1-step-ahead, the conditional reliability and error variance obtained from the abovementioned experiment were $99.6 \%$ and 3.437 respectively. Those results indicate that the asset will not break down for the next period of time (which can be in minutes, hours, days, etc.). For 6-steps-ahead, the asset reliability has reduced to 32.2\% which indicates a possible asset breakdown for the next period of time. 
Tjahjono, Teixeira, and Alfaro

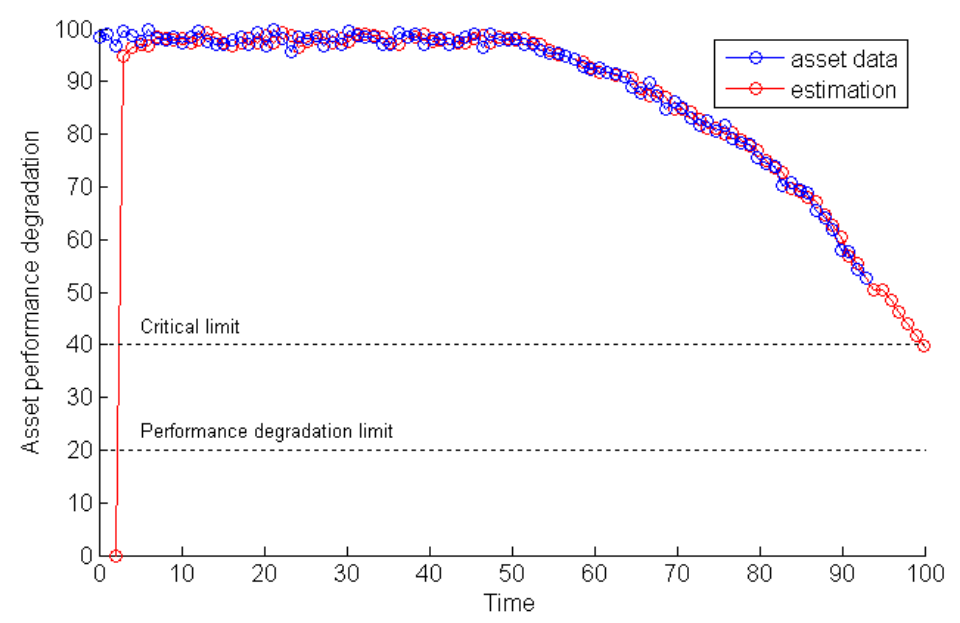

Figure 2: RE experimental validation

Table 1: RE experimental results

\begin{tabular}{|cccccc|}
\hline$i$ & $l$ & $h_{i}$ & $\hat{h}_{i+l 92}$ & $\hat{v}_{i+l \mid 92}^{2}$ & $R_{c \mid 92}$ \\
\hline 92 & 0 & 54.423 & 52.617 & 1.877 & 1.000 \\
\hline 93 & 1 & - & 50.528 & 3.437 & 0.996 \\
\hline 94 & 2 & - & 49.564 & 23.764 & 0.971 \\
\hline 95 & 3 & - & 48.363 & 47.950 & 0.936 \\
\hline 96 & 4 & - & 46.198 & 95.556 & 0.752 \\
\hline 97 & 5 & - & 44.034 & 144.820 & 0.524 \\
\hline 98 & 6 & - & 41.869 & 195.860 & 0.322 \\
\hline 99 & 7 & - & 39.705 & 248.790 & 0.176 \\
\hline 100 & 8 & - & 37.540 & 303.750 & 0.087 \\
\hline
\end{tabular}

\subsection{Engineering Services Simulation Model}

The engineering services online simulation model was developed using Anylogic ${ }^{\circ}$, a java-based

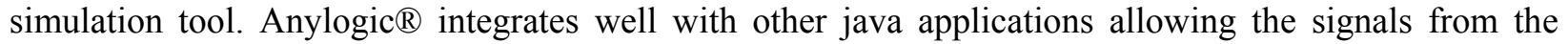
condition monitoring systems to be plugged-in to the model.

Figure 3 shows the screen shot of the online simulation model showing four machines being monitored under the engineering services contracts. Furthermore, each machine has its own maintenance regime which is based on condition monitoring data. The model can be used to test, in advance, operational requirements and possible service actions with the ultimate goal to guarantee high asset's capability. Each element of the model is an asset's representation (i.e. machines, service managers, technicians, data acquisition, etc.) with attributes and behaviors typically found in manufacturing systems.

At the front-end of the framework is the Data Capture (DC) module, a port which provides synchronized data to the simulation model. It collects the current asset's data from each condition monitoring enabled asset and updates its internal buffer. The internal buffer is an abstract representation from the parent simulation model (Hanisch, Tolujew, and Schulze 2005) where the model state corresponds to the current asset's state. Number of channels, sampling rate and asset address are the input parameters of the DC module. 
Tjahjono, Teixeira, and Alfaro



Figure 3: The online simulation model

The number of channels specifies how many channels that can be used to collect asset data. Sampling rate defines the frequency each channel must sample assets data. Even though the channels might use different sampling rate, the simulation model can only be updated after the elapsed time of the current completion horizon. The asset address is a virtual address for each channel. Once an asset model is used to represent a machine, it must be set to the same address in order to receive the message from the DC.

In contrast to traditional simulation where the simulation model runs over entire simulation time, in this model, the simulation time is split into completion horizons. Each completion horizon is an explicit rule which defines when the simulation engine must interrupt the simulation execution (Wynn et al. 2008). In the model, the completion horizon can be set as a function of jobs completed, absolute time duration or asset failure. In addition, the completion horizon can be compressed or relaxed accordingly. Due to the rapid increase of the uncertainty around the simulation outcomes for large completion horizon, the confidence function implemented into the model often checks the variance of the mission reliability estimation.

In the proposed framework, asset's failures are not based on probability distributions and MTBF information. They are determined by reliability estimation and other operating boundaries. An asset may fail whenever its mission reliability reaches any critical limits defined beforehand. Due to the fact that the asset might have different condition data and operating boundaries, one RE must be embedded into each asset model.

\section{EXPERIMENTATION}

Two simulation models (traditional discrete-event and online simulation models) were built as a basis for the experimentation and comparison. The discrete-event model is essentially the same as the online simulation model but without the Data Capture (DC) module. Both models are set with the same input parameters including MTBF and asset's lifetime.

Even though the MTBF does not directly related to the asset's lifetime due to wear-out failure period (Torell and Avelar 2011), in this case, it is a reasonable assumption made by most of maintenance practitioners and researchers, e.g. (Greenough and Grubic 2011), to adopt the same value when the wearout failure period is not included into asset lifetime (Moubray 1997). Additional input parameters, added 
into online simulation model, were needed to set the internal RE's parameters and do not affect the simulation outcomes. These input parameters are listed in Table 2.

Table 2 Input for the simulation models

\begin{tabular}{|c|c|c|c|c|}
\hline & Asset1 & Asset2 & Asset3 & Asset4 \\
\hline MTBF = exponential(x) & $1300 \mathrm{~h}$ & $1800 \mathrm{~h}$ & $2200 \mathrm{~h}$ & $1000 \mathrm{~h}$ \\
\hline $\operatorname{MTTR}=\operatorname{normal}(\mu, \sigma)$ & $3 \mathrm{~h}, 0.3 \mathrm{~h}$ & $14 \mathrm{~h}, 1.4 \mathrm{~h}$ & $4 \mathrm{~h}, 0.4 \mathrm{~h}$ & $9 \mathrm{~h}, 0.9 \mathrm{~h}$ \\
\hline OEM response time $=$ uniform $(\mathrm{x}, \mathrm{y})$ & $48 \mathrm{~h}, 72 \mathrm{~h}$ & $48 \mathrm{~h}, 72 \mathrm{~h}$ & $48 \mathrm{~h}, 72 \mathrm{~h}$ & $48 \mathrm{~h}, 72 \mathrm{~h}$ \\
\hline Contract duration & 15 years & 15 years & 15 years & 15 years \\
\hline \multicolumn{5}{|c|}{ Online Simulation - Input parameters } \\
\hline Asset's lifetime & $1300 \mathrm{~h}$ & $1800 \mathrm{~h}$ & $2200 \mathrm{~h}$ & $1000 \mathrm{~h}$ \\
\hline $\operatorname{MTTR}=\operatorname{normal}(\mu, \sigma)$ & $3 \mathrm{~h}, 0.3 \mathrm{~h}$ & $14 \mathrm{~h}, 1.4 \mathrm{~h}$ & $4 \mathrm{~h}, 0.4 \mathrm{~h}$ & $9 \mathrm{~h}, 0.9 \mathrm{~h}$ \\
\hline Constant smoothing & $0.6,0.6$ & $0.6,0.6$ & $0.6,0.6$ & $0.6,0.6$ \\
\hline Failure limits & $0.9,0.15$ & $0.9,0.15$ & $0.9,0.15$ & $0.9,0.15$ \\
\hline Reliability bounds & $95,85,60$ & $95,85,60$ & $95,85,60$ & $95,85,60$ \\
\hline Completion horizon & 5 hours & 5 hours & 5 hours & 5 hours \\
\hline OEM response time $=$ uniform $(\mathrm{x}, \mathrm{y})$ & $1 \mathrm{~h}, 24 \mathrm{~h}$ & $1 \mathrm{~h}, 24 \mathrm{~h}$ & $1 \mathrm{~h}, 24 \mathrm{~h}$ & $1 \mathrm{~h}, 24 \mathrm{~h}$ \\
\hline Contract duration & 15 years & 15 years & 15 years & 15 years \\
\hline
\end{tabular}

Three experiments were carried out to demonstrate the direct coupling mechanism, and to compare the outcomes of both models. In the first experiment (Exp1), assets are running under ideal operating and environment conditions. Likewise, the service contract is entirely executed without any requirement modifications. The results depicted in Table 3 indicate similar outcomes between both simulation models. Indeed, the online simulation outcomes point out a reduction of the number of breakdowns, asset utilization and availability improvement. Even though the difference in terms of breakdowns is relatively low (5 breakdowns for Asset1), this may become significant when the number of the high value assets increases.

In the second experiment (Exp2), dynamic behavior affected asset's lifetime (i.e. $20 \%$ reduction of the expected lifetime). It is a typical situation, where environment (e.g. temperature, humidity) and/or operating condition (unscheduled daily assets to meet unforeseen production demand), affects the expected asset's lifetime. The results obtained from Exp2 demonstrate a considerable difference in the outputs of both simulation models. As the traditional simulation model is not coupled with the real-time asset's condition data, it does not trigger current asset's lifetime variation. The outcomes obtained from the online simulation model execution show a reduction of $18.3 \%$ (on average) in MTBF and breakdowns increase $(22.7 \%$ on average) indicating a potential loss of revenue in the engineering service. These results can be used to alert the engineering service team in order to proactively act to find the potential source of problems, or possibly, to request contract modifications.

In the third experiment (Exp3), unforeseen circumstances also affect the expected asset's lifetime, but this time, due to the better maintenance regime, the lifetime increases by $\sim 20 \%$ from the expected lifetime. This information is valuable for the service provider because it can negotiate a contract extension that leads to additional source of revenue. Again, the traditional simulation fails into capture this business opportunity. On the other hand, the outcomes taken from the online simulation model suggests the lifetime increase for all the assets $(13.7 \%, 21.3 \%, 18.8 \%$ and $19.6 \%$ for the Asset1, Asset2, Asset3 and Asset4 respectively). Consequently, the number of the engineering service team interventions may be decreased leading to a more precise and timely maintenance, for instance. 


\section{Tjahjono, Teixeira, and Alfaro}

Table 3: Simulation outcomes obtained from the case studies

\begin{tabular}{|c|c|c|c|c|c|c|c|c|c|c|c|c|}
\hline \multicolumn{13}{|c|}{ imulation outputs and performance measures (traditional simulation) } \\
\hline & \multicolumn{3}{|c|}{ Asset1 } & \multicolumn{3}{|c|}{ Asset2 } & \multicolumn{3}{|c|}{ Asset3 } & \multicolumn{3}{|c|}{ Asset4 } \\
\hline & Exp1 & Exp2 & Exp3 & Exp1 & Exp2 & Exp3 & Exp1 & Exp2 & Exp3 & Exp1 & Exp2 & Exp3 \\
\hline Availability (\%) & 95.3 & 95.4 & 94.8 & 94.9 & 95.2 & 94.2 & 97.3 & 97.1 & 97.2 & 94.4 & 93.8 & 93.0 \\
\hline Jobs completed & 131,349 & 131,394 & 131,389 & 131,349 & 131,394 & 131,389 & 131,349 & 131,394 & 131,389 & 131,349 & 131,394 & 131,389 \\
\hline Utilization (\%) & 93.7 & 93,4 & 93.9 & 95.3 & 94.5 & 95.3 & 95.3 & 96.0 & 97.2 & 96.7 & 95.0 & 94.1 \\
\hline Breakdowns & 96 & 96 & 108 & 60 & 75 & 78 & 55 & 59 & 60 & 109 & 120 & 134 \\
\hline MTBF (h) & $1,282.0$ & $1,284.4$ & $1,142.0$ & $2,086.7$ & $1,655.0$ & $1,605.5$ & $2,276.4$ & $2.137,1$ & $2,127.9$ & $1,165.2$ & $1,039.8$ & 922,4 \\
\hline MTTR (h) & 63.3 & 61.4 & 63.1 & 74.0 & 73.0 & 72.6 & 63.2 & 64.2 & 63.0 & 68.7 & 68.6 & 69.8 \\
\hline \multicolumn{13}{|c|}{ Simulation outputs and performance measures (online simulation) } \\
\hline & Exp1 & Exp2 & Exp3 & Exp1 & Exp2 & Exp3 & Exp1 & Exp2 & Exp3 & Exp1 & Exp2 & Exp3 \\
\hline Availability (\%) & 98.8 & 98.7 & 99.0 & 98.6 & 98.3 & 98.8 & 99.3 & 99.2 & 99.4 & 98.1 & 97.6 & 98.3 \\
\hline Jobs completed & 131,394 & 131,392 & 131.394 & 131,394 & 131,392 & 131.394 & 131,394 & 131,392 & 131.394 & 131,394 & 131,392 & 131.394 \\
\hline Utilization (\%) & 98.1 & 98.6 & 98.1 & 97.3 & 97.5 & 97.4 & 98.3 & 98.9 & 97.6 & 97.9 & 97.2 & 97.8 \\
\hline Breakdowns & 91 & 114 & 80 & 69 & 84 & 57 & 55 & 69 & 46 & 121 & 143 & 101 \\
\hline $\operatorname{MTBF}(\mathrm{h})$ & $1,417.0$ & $1,136.4$ & $1,611.6$ & $1,852.1$ & $1,525.2$ & $2,246.2$ & $2,347.4$ & $1,883.0$ & $2,787.8$ & $1,063.6$ & 893.2 & $1,272.2$ \\
\hline MTTR (h) & 15.2 & 15.0 & 15.6 & 25.6 & 26.9 & 26.9 & 16.6 & 15.8 & 16.3 & 20.8 & 21.7 & 22.0 \\
\hline
\end{tabular}

\section{CONCLUDING REMARKS}

This paper proposes an online simulation that aims to provide better decision support in the context of operations and management of through-life engineering services. In particular, when the responsibility of the OEM is extended beyond manufacturing of the products to cover the maintenance support (e.g. through contractual agreements), the online simulation has shown considerable benefits in supporting operational decisions during the contract executions.

Unlike the traditional simulation methods where the focus is on evaluation of long-term business requirements, online simulation tool can be used to support short-term operational decisions typically occur in engineering services. Furthermore, proactive reaction to unforeseen circumstances can enable the engineering service team on timely maintenance so as to guarantee high asset availability and to minimize total through-life costs often required by all the stakeholders.

Three experiments were carried out in order to compare simulation outputs obtained from traditional simulation and online simulation models. The comparison between them indicates that, in the case where assets are affected by dynamic behavior, perturbation and other extreme environmental conditions, the online simulation can give a better picture of the assets availability, and this is particularly useful to support engineering services team.

Physically coupling the simulation model with the assets allows the condition of the asset to become a set of current state parameters which initialize the model and run the experimental scenarios. Variations in the expected performance can alert the engineering services team to take the immediate actions.

Industrial cases and more numerical analyses will continue to allow profit analysis from the reliable contract execution. Further investigations will also be conducted in order to evaluate different maintenance strategies, where condition monitoring module monitors more than one critical component. Additional investigation into operational service strategies and more sophisticated repair model will also be needed in order to further test the availability estimation. 
Tjahjono, Teixeira, and Alfaro

\section{REFERENCES}

Ng, I. Parry, G. McFarlane, D. and Tasker, P. 2011. "Towards a Core Integrative Framework for Complex Engineering Service Systems." In Complex Engineering Service Systems - Concepts and Research Current, Edited by I. Ng, G. Parry, P. J. Wild, D. McFarlane and P. Tasker, 1-19. SpringerVerlag London.

Purchase, V. Parry, G. and Mills, J. 2011. "Service Enterprise Transformation." In Complex Engineering Service Systems - Concepts and Research Current, Edited by I. Ng, G. Parry, P. J. Wild, D. McFarlane and P. Tasker, 25-47. Springer-Verlag London.

Lindahl, M. Sundin, E. Sakao, T. and Shimomura, Y. 2005. "An Application of a Service Design Tool at a Global Warehouse Provider." In 15th International Conference on Engineering Design: Engineering Design and the Global Economy, 2967-2978.

Rausand, M. and Hoyland, A. 2004. System reliability theory: models, statistical methods, and applications. 2nd Ed. Wiley Series in Probability and Statistics.

Ouertani, M. Z. Parlikad, A. K. and Mcfarlane, D. 2008. Towards an approach to select an asset information management strategy. The International Journal of Computer Science and Applications. $5,25-44$.

Tu, F. Ghoshal, S. Luo, J. Biswas, G. Mahadevan, S. Jaw, L. and Navarra, K. 2007. "PHM Integration with Maintenance and Inventory Management Systems." In 2007 Aerospace Conference, 1-12.

Dausch, M. and Hsu, C. 2005. Engineering service products: the case of mass-customising service agreements for heavy equipment industry. International Journal of Services Technology and Management. 7: 32-55.

Mobley, R. K. 2002. An introduction to predictive maintenance. 2nd Ed. Butterworth-Heinemann

Goffin, K. and New, C. 2001. Customer support and new product development - An exploratory study. International Journal of Operations \& Production Management. 21: 275-301.

Mattila, V. Virtanen, K. and Raivio, T. 2008. Improving Maintenance Decision Making in the Finnish Air Force through Simulation. Interfaces 38: 187-201.

Benedettini, O. and B. Tjahjono. 2009. Towards an improved tool to facilitate simulation modelling of complex manufacturing systems. The International Journal of Advanced Manufacturing Technology. 43: 191-199.

Markeset, T. and Kumar, U. 2003. Design and development of product support and maintenance concepts for industrial systems. Journal of Quality in Maintenance Engineering. 9: 376-392.

Hanisch, A. Tolujew, J. and Schulze, T. 2005. "Initialization of online simulation models." In Proceedings of the 2005 Winter Simulation Conference, Edited by M. E. Kuhl, N. M. Steiger, F. B. Armstrong, and J. A. Joines, 1795-1803.

Wynn, M. T. Dumas, M. Fidge, C. J. ter Hofstede, A. H. M. and van der Aalst, W. M. P. 2008. "Business Process Simulation for Operational Decision Support." In CBPM 2007 International Workshops, Edited by A. H. M. ter Hofstede, B. Boualem, and P. Hye-Young, 66-77. Springer-Verlag Berlin Heidelberg.

Lu, H. Kolarik, W. J. and Lu, S. S. 2001. Real-Time Performance Reliability Prediction. IEEE Transactions on reliability. 50: 353-357.

Gelper, S. Fried, R. and Croux, C. 2010. Robust forecasting with exponential and Holt-Winters smoothing. Journal of Forecasting. 29: 285-300.

LaViola, J. J. 2003. Double exponential smoothing: an alternative to Kalman filter-based predictive tracking. In Proceedings of the workshop on Virtual environments, 199-206. New York, NY, USA.

Yar, M. and Chatfield, C. 1990. Prediction intervals for the Holt-Winters forecasting procedure. International Journal of Forecasting. 6: 127-137.

NIST/SEMATECH. 2011. e-Handbook of Statistical Methods. Available from: http://www.itl.nist.gov/div898/handbook/ [Accessed: 14 ${ }^{\text {th }}$ Jan 2011]. 
Torell, W., and Avelar, V. 2011. Mean Time Between Failure: Explanation and Standards. Available from: www.ptsdcs.com/whitepapers/57.pdf [Accessed: 12 ${ }^{\text {th }}$ May 2011].

Greenough, R. M. and Grubic, T. 2011. Modelling condition-based maintenance to deliver a service to machine tool users. The International Journal of Advanced Manufacturing Technology. 52:11171132.

Moubray, J. 1997. Reliability centered maintenance. 2nd Ed. Industrial Press Inc., New York, EUA

\section{AUTHOR BIOGRAPHIES}

BENNY TJAHJONO is a Senior Lecturer in Manufacturing Systems Engineering and the Director of the Manufacturing Masters Programme at Cranfield University. He holds a first degree in Electrical Engineering, an MSc and a PhD both in Manufacturing Systems Engineering from Cranfield University. His background in Electrical Engineering and Manufacturing Systems Engineering has guided his research interests towards the multidisciplinary area of simulation modeling and condition monitoring of assets. He is currently leading a research team in the area of contemporary simulation modeling techniques and applications. He has been working closely with global companies such as Ford and RollsRoyce on a number of industrial research projects associated with the decision making process and analysis/design of manufacturing systems. His email address is b.tjahjono@cranfield.ac.uk.

EVANDRO LEONARDO SILVA TEIXEIRA is an Associate Lecturer at the Faculdade Gama, Universidade de Brasília, Brazil. He is currently working on research project that aims to harness Prognostics and Health Management and Product-Service System to support operational decisions. Before this he had worked at the Autotrac Comércio e Telecomunicações S/A company for 2 years designing fleet management solutions for automotive industry. He has earned his MSc in Mechatronic System at the Universidade de Brasília, Brazil and his BSc in Electromechanical at the Centro Federal de Educação Tecnológica de Goiás, Brazil. His research interests include: Automotive electronics, Integrated Vehicle Health Management, Industrial Product-Service System. His email address is evandroleonardo@unb.br.

SADEK CRISÓSTOMO ABSI ALFARO is a Professor at the Departamento de Engenharia Mecânica, Universidade de Brasília, Brazil. He was Postdoctoral Research Fellow and has awarded his PhD in Welding Engineering at the School of Industrial and Manufacturing Science, Cranfield University, UK. He has earned his MSc in Metallurgical and Mining Engineering, Universidade Federal de Minas Gerais (1983), Brazil, and his BSc in Mechanical Engineering, Universidade Federal do Rio Grande do Sul, Brazil. He is the leader of the Automation and Control Group (GRACO) and has also launched the undergraduate course in Mechatronic Engineering at the Universidade de Brasília, Brazil. His research interests include: Manufacturing Automation and Control, Robotization and Welding Process Automation. His email address is sadek@unb.br. 